\title{
Developing an Articulation Test for Arabic-Speaking School-Age Children
}

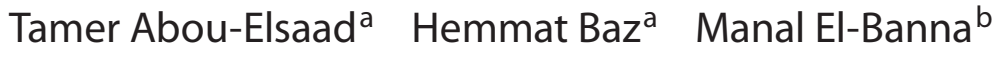 \\ Phoniatric Unit, ORL Department, Faculty of Medicine, a Mansoura University, Mansoura and \\ ${ }^{\mathrm{b}}$ Alexandria University, Alexandria, Egypt
}

\section{Key Words}

Arabic articulation test - Arabic phonology • Phonological disorders

\begin{abstract}
Objective: The aim of this study was to develop an Arabic articulation test using familiar and visually transparent words in order to be used as a criterion for comparing phonemes of both normal and phonologically disordered Arabic-speaking children. Material and Methods: A picture-naming test was designed for the Mansoura Arabic Articulation Test (MAAT) to elicit spontaneous single-word responses representing all possible consonant positions and vowels of Colloquial Egyptian Arabic. Three expert phoniatricians were asked to review MAAT and complete a questionnaire. The MAAT was presented to 100 normal Arabic-speaking Egyptian children randomly selected from the first- and secondgrade kindergarten. They were 52 males and 48 females with ages ranging between 42 and 70 months. Children's responses were converted to a percent correct score for sound utterances and picture identification. Results: Statistically non-significant differences were found among experts' opinions reflecting approval for the MAAT items. A statistically highly significant adequate correlation was found between correct word utterances and picture identification which proved the content validity of MAAT. Test-retest reliability proved the consistency of MAAT. Conclusion: MAAT is a valid and reliable test that can be applied to collect the phonetic inventory of Arabic-speaking young children.
\end{abstract}

Copyright $\odot 2009$ S. Karger AG, Basel

\section{KARGER}

Fax +4161306 1234 E-Mail karger@karger.ch www.karger.com

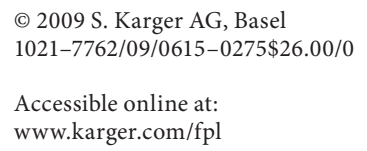

\section{Introduction}

Arabic is a Semitic language spoken by more than 422 million people (Microsoft, Encarta Encyclopedia ${ }^{\circledR}, 2004$ ). The classical Arabic language is particularly applied on the academic and religious levels. The colloquial Arabic dialects spoken by Arabs differ significantly in each Arab country; nevertheless, they are all mutually intelligible. Colloquial Egyptian Arabic (CEA) is a dialect of Arabic which consists of 27 consonant phonemes with a wide range of places of articulation that span the whole vocal tract from lips to glottis. Its vowel system is relatively simple with eight vowel phonemes (described below) [1].

The consonant inventory of CEA includes the primary emphatic phonemes / $\underline{\mathrm{t}} /, / \underline{\mathrm{d}} /, / \underline{\mathrm{s}} /$, , $/$, which causes the Arabic language to be distinguished from the great majority of European languages. These emphatic phonemes physiologically differ from their non-emphatic counterparts $/ \mathrm{t} /, / \mathrm{d} /, / \mathrm{s} /, \mathrm{z} /$ in the retraction of the tongue root to approach the posterior pharyngeal wall, accompanied by depression of the posterior part of the tongue $[2,3]$. Consequently, the pharyngeal cavity is small and the oral cavity is large in a way that provides a compartment that is presumably responsible for the characteristic feature of emphatic resonance $[4,5]$. CEA also includes the phoneme /q/, which is often substituted by / $/$ / in CEA, with only few exceptional words absorbed from classical Arabic. The Arabic inventory includes back consonants that are either glottal $(/ \mathrm{l} /)$, velar $(/ \mathrm{x} /, / \gamma /)$ or pharyngeal $(/ \mathrm{h} /$, $/ \mathrm{i} /)[6]$. 
There are eight vowel phonemes in CEA, five long $(/ \mathrm{i}$ :, e:, $\alpha$ :, o:, u:/) and three short $(/ \alpha, \mathrm{i}, \mathrm{u} /)$ [1, 7]. Vowels do not occur in initial position, and there are no diphthongs in CEA [1].

When the speech of a child is unintelligible, subjective estimates of intelligibility are not very useful for diagnosis or treatment planning; an articulation test is an objective, better alternative [8]. Fluharty [9] stated that there is always a need for articulation tests that are culturally and phonemically plausible, easy, comprehensive, quick-toadminister, highly reliable and valid, and represent basic norms for the articulation competence in children.

In fact, the actual need to test children whose mother tongue is Arabic led to the emergence of many articulation tests $[4,10-12]$. However, not all CEA consonants are represented in these tests; equally, not all the possible consonant positions in the word are tested and none includes explicit vowel testing.

The aim of this prospective pilot study was to develop an Arabic articulation test using familiar, culturally based and visually transparent words in order to be used as a criterion for comparing phonemes of both normal and phonologically disordered Arabic-speaking children.

\section{Material and Methods}

The Mansoura Arabic Articulation Test (MAAT) passed through the following stages: (1) design stage, (2) validation stage, (3) test application stage, and (4) reliability stage.

\section{Design Stage}

A picture-naming test including 106 pictures was designed to elicit spontaneous single-word responses representing all possible initial, middle, final and double positions of CEA consonants and the eight CEA vowels.

The MAAT has two sections: section A consists of 25 CEA consonants. Consonants /q/ and $/ \theta /$ are not included as they are always replaced by $/ \mathrm{T} /$ and $/ \mathrm{t} /$, respectively, in the CEA dialect. Section B consists of 8 words presenting the long and the short vowels. Both sections contain words that are culturally proper, familiar to young children and above all that can be pictured without ambiguity ('Appendix'). All photos representing the test words are in full color. However, the authors could not find familiar words for young children representing double consonants for the phonemes $/ \mathrm{h} /$ and $/ \underline{z} /$.

\section{Validation Stage}

In this case, validity refers to the extent to which the test can evaluate the true articulation abilities of children in the tested age range. Three judges, who are expert phoniatricians, were asked to review the constructed test and complete a questionnaire covering the following items:
(1) Is the tested age group suitable to ascertain the quality of the material used in this test?

(2) Are the chosen words familiar and culturally suitable for CEA children?

(3) Is the position of the tested consonant in the word suitable for the intended tested position?

(4) Are double-consonant words helpful in pushing the children's skills to the limit?

(5) Is the addition of vowels to this test useful? If the answer is yes, do the chosen words represent the chosen vowels?

(6) Do the pictures represent the tested words? If the answer is no, please enumerate these photos.

(7) Are the pictures of good resolution and sufficiently clear? If the answer is no, please mark the photos and add your comment on each one.

(8) If the photos presenting the word are unfamiliar to the child, is it suitable to pronounce the word to the child directly and/or with cues?

(9) Any suggestions for the test in general?

\section{Test Application Stage}

The MAAT was presented to 100 monolingual Arabic-speaking Egyptian children randomly selected from the first- and second-grade kindergarten level of education. They were 52 males and 48 females with ages ranging between 42 and 70 months (mean was $56.06 \pm 7.962$ months). Both boys and girls were selected for the study to evaluate whether there is a potential sex effect. All children came from families living in Mansoura (Dakahlia State, Egypt) and had roughly the same socio-economic status.

Children were assessed according to their phonological development, conversational skills, and syntactically correct use of at least five-word sentences. Both teacher's impression with regard to the children's performance at the nursery and the parents' impression of their children's language development was definitely considered. Children were screened formally and those with delayed language development, hearing and/or visual impairment, children with learning disability as well as children with orofacial disorders were excluded from this study.

Each child was tested individually in a 15- to 20-min session in a quiet room. When necessary other familiar people remained in the room but were asked not to assist the child in any way. Picture-naming and/or question/answer were used to elicit the response from the child. For example, the examiner asked, 'What is this?' and the child responded by naming the picture. If the child did not name the picture spontaneously, additional cues were given. These included questions, prompts, and delayed imitation of the examiner (who pronounced the word at habitual pitch and loudness).

A score of 1 was given to the child if he/she could utter the word correctly for each tested sound position and a score of 0 for no response or incorrect productions. The criteria for recording incorrect responses were taken from the study by Mullen and Whitehead [13]. Incorrect responses included words other than the desired response, a faulty singular or plural form of the word or any abbreviation or mispronunciation of the desired response. The perceptual part of the test (children's ability to identify the pictures) was also evaluated. A score of 1 was given to the child if he/she could identify the picture representing the tested word correctly and a score of 0 for their failure to identify the picture. Children's responses were converted to a percent correct score. 
Reliability Stage

Reliability is synonymous with the consistency of a test, survey, observation, or other measuring device. Test-retest reliability refers to the test's consistency among different administrations. One major concern with test-retest reliability is what has been termed 'the memory effect', especially when the two administrations are close together in time. MAAT reliability was examined using the test-retest method and the same children were retested 5 weeks later with the same examiner under similar circumstances.

Statistical Measures and Analysis. Frequency, mean and standard deviation were used to describe data. To test for the significance of change, $t$ test was applied to compare two means, and ANOVA was used to compare more than two means; $p$ value was considered significant if $\leq 0.05$. Pearson's correlation coefficient was used to detect the linear relationship between two quantitative variables. Spearman's rho correlation coefficient was used for estimating test reliability. Reliability was scaled as follows: $<0$ 0.25 weak reliability, $0.25-0.75$ moderate reliability, $0.75-<1$ strong reliability and 1 is optimum. The SPSS program (version 13) was used for statistical purposes.

\section{Results}

Interpretation of scoring results of MAAT is presented in three sections: (1) validity of judgments, (2) results of test application, and (3) reliability results.

\section{Validity of Judgments}

The responses of the 3 judges to the questionnaire are summarized in table 1 . The three judges agreed that the pictures for /to.fæhæ/ apple, /be: $\underline{d} /$ eggs and /t $\alpha \lg /$ ice were unclear and recommended that they better be photographed again. One of the judges asked to replace the word / $\int \alpha$. ga.ra/ tree by the word / $\alpha \alpha$.r $\alpha$. bej.ja/ car in testing the mid position of the $/ \mathrm{r} /$ sound, and to replace the

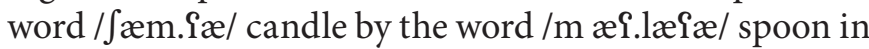
testing the mid position of the / $/$ / sound. The percentages of word suitability, representing the tested consonants and the corresponding pictures from the judges' point of view, and the percentages of agreement among the 3 judges about the other questionnaire items are summarized in table 2 . Statistically speaking, non-significant differences were detected among the judges' opinions using one-factor ANOVA test $(\mathrm{p}>0.05)$.

\section{Results of Test Application}

Item Difficulty

Item difficulty (i.e. the percent of examinees that pass a given item) was determined to identify items that are too difficult (table 3 ). At least $25 \%$ of children should be able to correctly identify a picture, otherwise it was replaced or removed.
Table 1. Summary of the responses of the judges to the questionnaire

\begin{tabular}{llll}
\hline Items & Judge 1 & Judge 2 & Judge 3 \\
\hline $\begin{array}{l}\text { Chosen age group } \\
\text { Suitability of the words for the } \\
\text { tested consonant/vowel position }\end{array}$ & yes & yes & yes \\
\hline $\begin{array}{l}\text { Suitability of adding double- } \\
\text { consonant words to push the } \\
\text { children's skills to the limit }\end{array}$ & yes & yes & yes \\
\hline $\begin{array}{l}\text { Suitability of adding basic vowel } \\
\text { words to the test }\end{array}$ & yes & yes & yes \\
\hline $\begin{array}{l}\text { Allowing the child to pronounce } \\
\text { the word after the examiner in } \\
\text { cases of difficult words }\end{array}$ & yes & yes & no \\
$\begin{array}{l}\text { Use of cues to elicit the child's } \\
\text { response to pictures instead of } \\
\text { direct pronunciation of difficult }\end{array}$ & yes & yes & yes \\
words & & & \\
\hline
\end{tabular}

Yes = Agree; no $=$ does not agree.

Table 2. Comparison of the judges' opinions to the questionnaire items in percent scores

\begin{tabular}{llll}
\hline Judges & $\begin{array}{l}\text { Suitability } \\
\text { of the } \\
\text { tested word }\end{array}$ & $\begin{array}{l}\text { Suitability of } \\
\text { the corresponding } \\
\text { picture }\end{array}$ & $\begin{array}{l}\text { Other } \\
\text { questionnaire } \\
\text { items }\end{array}$ \\
\hline First & $86.73 \pm 0.34$ & $97.96 \pm 0.14$ & $100 \pm 0.00$ \\
Second & $88.78 \pm 0.32$ & $96.94 \pm 0.17$ & $100 \pm 0.00$ \\
Third & $86.73 \pm 0.34$ & $95.92 \pm 0.20$ & $87.5 \pm 0.35$ \\
Mean \pm SD & $87.42 \pm 1.18$ & $96.94 \pm 1.02$ & $95.83 \pm 7.22$ \\
F & 0.39 & 1.00 & 1.00 \\
p & 0.680 & 0.372 & 0.351 \\
\hline
\end{tabular}

$\mathrm{F}=$ Repeated measures ANOVA; $\mathrm{p}>0.05$ (non-significant).

The mean percent of correct sound utterances, except in double-consonant position, was $100 \%$ in all children in the first and second application of MAAT. The mean percentage of correct double-consonant utterances was $97.64 \pm 7.1$ and $99.04 \pm 3.6$ after the first and second application of MAAT, respectively. The mean scores of correct picture identification were $93.25 \pm 17.8$ and $97.85 \pm$ $5.4 \%$ for consonants and $96 \pm 17.8$ and $100 \%$ for vowels

Folia Phoniatr Logop 2009;61:275-282 
Table 3. Percent of correct responses for every item for both sound utterances and picture identification for consonants and vowels in the first application of MAAT

a Tested consonants

\begin{tabular}{|c|c|c|c|c|c|c|c|c|}
\hline \multirow{2}{*}{$\begin{array}{l}\text { Tested } \\
\text { conso- } \\
\text { nants }\end{array}$} & \multicolumn{2}{|c|}{ Initial } & \multicolumn{2}{|c|}{ Medial } & \multicolumn{2}{|c|}{ Final } & \multicolumn{2}{|c|}{ Doubled } \\
\hline & $\mathrm{CU}$ & IP & $\mathrm{CU}$ & IP & $\mathrm{CU}$ & IP & $\mathrm{CU}$ & IP \\
\hline /P/ & 100 & 55 & 100 & 100 & 100 & 100 & 100 & $55^{\mathrm{a}}$ \\
\hline /b/ & 100 & 100 & 100 & 100 & 100 & 100 & 100 & 100 \\
\hline$/ \mathrm{t} /$ & 100 & 100 & 100 & 100 & 100 & 100 & 100 & 100 \\
\hline /g/ & 100 & 100 & 100 & 100 & 100 & 100 & 95 & $70^{\mathrm{a}}$ \\
\hline$/ \hbar /$ & 100 & 100 & 100 & 100 & 100 & 100 & - & - \\
\hline$|x|$ & 100 & 81 & 100 & 100 & 100 & 100 & 70 & $15^{\mathrm{b}}$ \\
\hline /d/ & 100 & 100 & 100 & 100 & 100 & 100 & 100 & $45^{\mathrm{a}}$ \\
\hline$/ \mathrm{r} /$ & 100 & 100 & 100 & 100 & 100 & 100 & 100 & 100 \\
\hline$|\mathrm{z}|$ & 100 & 100 & 100 & 100 & 100 & 100 & 100 & 100 \\
\hline /s/ & 100 & 100 & 100 & 91 & 100 & 100 & 100 & 100 \\
\hline / $/$ & 100 & 100 & 100 & 100 & 100 & 100 & 100 & 100 \\
\hline /s/ & 100 & 100 & 100 & 100 & 100 & 100 & 100 & 100 \\
\hline / $/$ & 100 & $100^{\mathrm{a}}$ & 100 & 100 & 100 & 100 & 100 & $62^{\mathrm{a}}$ \\
\hline$/ \underline{\mathrm{t}} /$ & 100 & 100 & 100 & 100 & 100 & 100 & 100 & 100 \\
\hline$|\underline{z}|$ & 100 & 100 & 100 & $100^{\mathrm{a}}$ & 100 & $60^{\mathrm{a}}$ & - & - \\
\hline$/ \bar{\Phi} /$ & 100 & 100 & 100 & 100 & 100 & 100 & 100 & 45 \\
\hline$|\gamma|$ & 100 & 100 & 100 & 76 & 100 & 89 & 82 & $89^{a}$ \\
\hline /f/ & 100 & 100 & 100 & 91 & 100 & 100 & 100 & 81 \\
\hline /k/ & 100 & 100 & 100 & 100 & 100 & 100 & 100 & 100 \\
\hline /l/ & 100 & 100 & 100 & 100 & 100 & 100 & 100 & 100 \\
\hline$/ \mathrm{m} /$ & 100 & 100 & 100 & 100 & 100 & 100 & 100 & 100 \\
\hline$/ \mathrm{n} /$ & 100 & 100 & 100 & 100 & 100 & 100 & 100 & 100 \\
\hline /h/ & 100 & 86 & 100 & $84^{\mathrm{a}}$ & 100 & 100 & 100 & $86^{\mathrm{a}}$ \\
\hline /w/ & 100 & 100 & 100 & 100 & 100 & 100 & 100 & $11^{\mathrm{b}}$ \\
\hline /j/ & 100 & $87^{\mathrm{a}}$ & 100 & 100 & 100 & 100 & 100 & $60^{\mathrm{a}}$ \\
\hline
\end{tabular}

$\mathrm{CU}=$ Correct utterance; $\mathrm{IP}=$ identified picture.

${ }^{\text {a }}$ Identified with cues.

${ }^{\mathrm{b}}$ Unfamiliar picture.

b Tested vowels

\begin{tabular}{lll}
\hline Tested vowels & Correct utterance & Identified picture \\
\hline /i/ & 100 & 100 \\
/i:/ & 100 & 100 \\
/e:/ & 100 & 100 \\
/ $\alpha /$ & 100 & 100 \\
/ $\alpha: /$ & 100 & 100 \\
/o:/ & 100 & 100 \\
/u/ & 100 & 100 \\
/u:/ & 100 & $65^{\mathrm{a}}$ \\
\hline
\end{tabular}

${ }^{a}$ Identified with cues. after the first and second application of MAAT, respectively (table 4).

After the first application of MAAT, we found that the following pictures were unclear to children: /?r.næb/ rabbit, /bær.?u:?/ plum, /gær.gi:r/ jarjir, / $\chi \alpha$.ru:f/ sheep, /du:.dæ/ worm, / / $\alpha . \underline{\mathrm{d}} \alpha . \underline{\mathrm{d}} \alpha /$ teether, / $\alpha$ l.m $\alpha: \underline{z} /$ diamond, /mo.y æn.ni/ singer, /nei.næ:i/ mint, /ju.ju/ yoyo and /fu:l/ beans. These unclear pictures were photographed again and presented to the children in the second application of the test.

Cues were used in the following words: /bær.?u:?/ plum, /gær.gi:r/ jarjir, /du:.dæ/ worm, /dof.d $\alpha \mathrm{i} /$ frog,

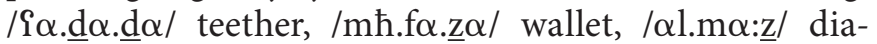

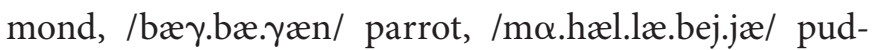
ding, /hod.hod/ hoopoe, /jas.mi:n/ jasmine, /ju.ju/ yoyo and /fu:1/ beans.

The following pictures were unfamiliar to children:

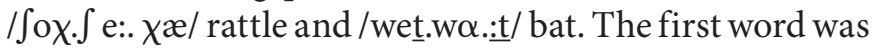
replaced by $/ \chi 0 \chi /$ peach. However, the authors could not find familiar words for young children representing the double-consonant position for the phoneme /w/; thus, it was removed from the test.

Discriminating Validity for the MAAT Items

Statistical analysis was further applied to identify items to the advantage of one group rather than the other according to age and gender.

In an attempt to examine the effect of age on MAAT performance, the children were divided into three groups according to age: group 1, 42 months to less than 4 years (17 children); group 2, 4-5 years (44 children); group 3, above 5 years (39 children). Statistically, highly significant differences were found among the three age groups with better performance in older children (table 5). On the other hand, statistically non-significant differences were found in the performance of males and females on MAAT (table 6).

\section{Content Validity}

Content validity is the extent to which the content of a test is representative of the conceptual domain that it was designed to cover [14]. A statistically significant and a highly adequate correlation was found between correct word utterance and picture identification $(\mathrm{r}=0.91, \mathrm{p}=$ $0.00)$.

\section{Test Reliability}

The mean percentages of correct scores for the MAAT items were subjected to test-retest reliability measures. It was found that the reliability coefficient for correct con- 
Table 4. Descriptive data for percent correct scores for sound utterances and identified pictures after the first and second applications of MAAT (mean $\pm \mathrm{SD})$

\begin{tabular}{|c|c|c|c|c|c|c|}
\hline & & Initial & Middle & Final & Double & Total \\
\hline \multirow[t]{2}{*}{ Correct consonant utterances } & 1 st & $100 \pm 0.0$ & $100 \pm 0.0$ & $100 \pm 0.0$ & $97.64 \pm 7.1$ & $97.45 \pm 3.5$ \\
\hline & $2 \mathrm{nd}$ & $100 \pm 0.0$ & $100 \pm 0.0$ & $100 \pm 0.0$ & $99.04 \pm 3.6$ & $99.75 \pm 1.8$ \\
\hline \multirow{2}{*}{$\begin{array}{l}\text { Picture identification for } \\
\text { consonants }\end{array}$} & 1 st & $99.92 \pm 0.4$ & $97.64 \pm 7.4$ & $95.4 \pm 17.3$ & $83.1 \pm 24.0$ & $93.25 \pm 17.8$ \\
\hline & 2nd & $98.56 \pm 4.0$ & $98.96 \pm 3.8$ & $99.56 \pm 2.2$ & $94 \pm 8.4$ & $97.85 \pm 5.4$ \\
\hline \multirow[t]{2}{*}{ Correct vowel utterances } & $1 \mathrm{st}$ & & & & & $100 \pm 0.00$ \\
\hline & 2nd & & & & & $100 \pm 0.00$ \\
\hline \multirow[t]{2}{*}{ Picture identification for vowels } & 1 st & & & & & $96 \pm 17.8$ \\
\hline & $2 \mathrm{nd}$ & & & & & $100 \pm 0.00$ \\
\hline
\end{tabular}

Table 5. Comparison among three age groups and their performance on MAAT (mean $\pm \mathrm{SD})$

\begin{tabular}{|c|c|c|c|c|c|c|}
\hline & $\begin{array}{l}\text { Group } 1 \\
<4 \text { years } \\
(n=17)\end{array}$ & $\begin{array}{l}\text { Group } 2 \\
4-5 \text { years } \\
(\mathrm{n}=44)\end{array}$ & $\begin{array}{l}\text { Group } 3 \\
>5 \text { years } \\
(n=39)\end{array}$ & Total & $\mathrm{F}$ & Sig. \\
\hline Correct CU, n & $97.35 \pm 0.70$ & $97.77 \pm 0.52$ & $97.76 \pm 0.27$ & $97.76 \pm 0.51$ & 8.37 & $0.00^{*}$ \\
\hline Correct VU, n & $8 \pm 0.00$ & $8 \pm 0.00$ & $8 \pm 0.00$ & $8 \pm 0.00$ & - & - \\
\hline Identified pictures for $\mathrm{C}, \mathrm{n}$ & $97.29 \pm 0.69$ & $97.77 \pm 0.52$ & $97.92 \pm 0.27$ & $97.75 \pm 0.52$ & 10.4 & $0.00^{*}$ \\
\hline Identified pictures for $\mathrm{V}, \mathrm{n}$ & $8 \pm 0.00$ & $8 \pm 0.00$ & $8 \pm 0.00$ & $8 \pm 0.00$ & - & - \\
\hline
\end{tabular}

ANOVA test, ${ }^{*} \mathrm{p}<0.001$ (highly significant). CU $=$ Consonant utterance; $\mathrm{VU}=$ vowel utterance.

Table 6. Comparison of the performance of children according to gender on MAAT (mean \pm SD)

\begin{tabular}{|c|c|c|c|c|}
\hline & $\begin{array}{l}\text { Male } \\
(\mathrm{n}=48)\end{array}$ & $\begin{array}{l}\text { Female } \\
(\mathrm{n}=52)\end{array}$ & $\mathrm{t}$ & $\mathrm{p}$ \\
\hline Age, months & $55.46 \pm 7.32$ & $52 \pm 56.62$ & -0.72 & 0.47 \\
\hline Correct consonant utterances, $\%$ & $97.77 \pm 0.52$ & $97.75 \pm 0.52$ & 0.20 & 0.84 \\
\hline Correct vowel utterances, \% & $100 \pm 0.00$ & $100 \pm 0.00$ & - & - \\
\hline Identified pictures, $\%$ & $99.77 \pm 0.47$ & $99.77 \pm 0.56$ & 0.38 & 0.70 \\
\hline
\end{tabular}

t test, $\mathrm{p}>0.05$ (non-significant). sonant utterance was 0.75 and for picture identification, representing the tested consonants, was 0.66 . Test-retest reliability for correct vowel utterance and the identification of corresponding pictures could not be determined, since no variability was noticed.

When MAAT reliability was examined according to children's age, we found that the reliability coefficient for children less than 5 years of age ( 37 children) was better than that for picture identification. On the other hand, older children more than 5 years of age (63 children) had better correct word utterance reliability. When MAAT reliability was examined according to children's gender, the reliability coefficients for both picture identification and correct word utterance were scored better in females than males (table 7). 
Table 7. Spearman's correlation coefficient for reliability of MAAT according to age and gender

\begin{tabular}{lllllll}
\hline & \multicolumn{2}{l}{ Age } & & \multicolumn{2}{l}{ Sex } & \\
\cline { 2 - 3 } \cline { 5 - 6 } & $<5$ years & $>5$ years & & male & female \\
\hline Correct word utterances & 0.78 & 0.80 & & 0.70 & 0.78 \\
Picture identification & 0.70 & 0.46 & & 0.58 & 0.70 \\
\hline
\end{tabular}

\section{Discussion}

The sound development in children reflects indirectly the phonological mastery during their language acquisition. Emerging sounds are often produced more accurately in response to articulation test stimuli [15]. Testing the accuracy of speech sound production is essential for the diagnosis and the intervention planning for disorders of articulation. Articulation tests are relatively quick and easy to administer and score. They help to collect information on a child's phonetic inventory, by recording his/ her production of each consonant on the test, in each word position, thus suggesting to what extent the child knows how to produce the sounds [8]. They also show whether a child is significantly lagging behind normal phonological development.

The use of articulation tests is required if the phonology problem is related to articulation errors, like, for instance, when distortions and substitutions are consistent across every instance of a particular sound, regardless of its position or when errors are few on individual sounds and do not generalize across the class of the sounds [8]. Not only the accuracy of consonant production is affected in speech disorders, but also definite vowel distortions have been documented [16]. Thus, articulation tests provide indices for areas that need to be addressed during intervention.

MAAT has been designed to include all the CEA consonants in all possible consonant positions in the word. Furthermore, testing the double-consonant position in words is included in MAAT with the hypothesis to push the children's skills to the limit. The CEA vowels are also supposed to be used in speech diagnosis and language disorders that may include vowel distortions, e.g. dysarthria.

Statistics for judge validity for the MAAT revealed no significant differences among the judges' opinions. The percentage of agreement about word suitability, representing the tested sounds and the corresponding pictures from the judges' point of view, and the percentage of agreement about the other questionnaire items exceeded $85 \%$. This indicates not only stability among the judges' opinions but also a high percentage of approval for the selected test materials.

Although the mean percent of correct consonant utterances in initial, middle and final positions and the mean percent of correct vowel utterances were $100 \%$ in all studied children, double-consonant words challenged younger children. This could be attributed to the fact that the double-consonant position in the word might provoke an articulatory breakdown in them. On the other hand, older children were old enough to have reached a full development of the phonological system $[5,17,18]$. This is also true for the statistically highly significant, better overall, mean, and correct score of picture identification in older children, due to their more developed mental abilities and experience.

Interestingly, common articulatory errors especially for young children were in the double velar consonant $/ \mathrm{x} /$ and its voiced cognate $/ \gamma /$. These consonants are not found in English and are not common in other languages. These problematic consonants are those that most differ from typical European consonant inventories. This raises the possibility of a number of interesting future studies of these differences regarding the performance of normally developing children in Arabic and European languages on analogous articulation tests.

Although MAAT reliability was better in females than males, statistically non-significant differences were found in the performance of males and females on MAAT. This indicates the applicability of this test for both sexes, giving fairly similar results. This agrees with the study by Amayreh and Dyson [4], that found no difference between the performance of girls and boys at any age for their Arabic articulation test.

In the design of MAAT, special consideration was given to the elimination of abstract pictures, to unveiling picture ambiguity and bringing about the consistency of responses. Templin and Darley [19] stated that in designing and using an articulation test 'pictures should be utilized which have been tested for their efficiency in eliciting responses'. In this study, descriptive analysis of the children's accurate responses was not markedly changed for the pictures that were replaced. This suggests that vocabulary, rather than visual imagery, is the important variable in picture ambiguity. Moreover, the statistically highly significant correlation between correct word utterance and picture identification in this study indicates the suitability of the chosen pictures and their representation of the tested word. This significant correlation proves the 
content validity of MAAT because it demonstrates a requirement for the child to be able to perceive a word to produce it correctly. Thus, the study strongly supports the conclusions drawn by Shanks et al. [20] and Madison et al. [21] that picture stimuli should be pretested for content effectiveness prior to inclusion in diagnostic instruments that are designed to elicit a specific language sample.

In this study, the difference in reliability between correct consonant utterance and picture identification results from the fact that the child may be unable to identify the picture representing the tested word but still be able to utter the word correctly when given additional cues. So the examiner gave him/her a correct response for the consonant pronunciation but incorrect response for picture identification. This can explain the strong reliability that is found for correct consonant utterance and the moderate reliability for picture identification. However, this still proves the consistency of MAAT items.

\section{Conclusion}

MAAT is a valid and reliable test that can be applied to collect the phonetic inventory of Arabic-speaking young children. Further studies are recommended to apply MAAT on patients with phonological and speech disorders.

\section{Acknowledgements}

The authors express their deep appreciation to Prof. Dr. Safa Elsady; Prof. Dr. Mahmoud Youssef Abou-ElElaa and Prof. Dr. Marwa Saleh, Prof. of Phoniatrics, Ain Shams Faculty of Medicine, Cairo, Egypt for their valuable comments and feedback during the construction of MAAT.

\section{Appendix}

Mansoura Arabic Articulation Test

A Consonants

\begin{tabular}{|c|c|c|c|c|}
\hline Consonant & Initial & Middle & Final & Double \\
\hline$/ \mathrm{P} /$ & /Pr.næb/ rabbit & $/ \mathrm{m} \alpha .1 \alpha \underline{\mathrm{s}} / \mathrm{scissor}$ & /bo?/ mouth & /bær.?u:?/ plum \\
\hline /b/ & /bent/ girl & $/ \underline{\mathrm{t} \alpha} \alpha . . \mathrm{b} \alpha . \bar{\imath} / \mathrm{dish}$ & /؟e.næb/grapes & $/ \mathrm{b} \alpha: \mathrm{b} /$ door \\
\hline$/ \mathrm{t} /$ & /to.fæhæ/ apple & /ke:t $\alpha \mathrm{b} /$ book & /kæb.ri:t/ match & /to:r.t $\alpha /$ cake \\
\hline /g/ & /gæ.mæl/ camel & / Iæ.gæ.læ/ bick & $/$ t $\alpha \lg /$ ice & /gær.gi:r/ jarjir \\
\hline$/ \hbar /$ & /ho.m $\alpha$ r/ donkey & /mor.ge:.ћæ/ swing & /bæ.læh/ date & - \\
\hline$|x|$ & 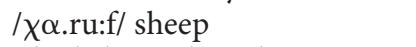 & 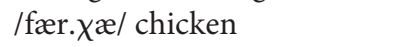 & /bot.tit: $\chi /$ watermelon & $/ \chi 0 \chi /$ peach \\
\hline /d/ & /du:.læb/ cupboard & /mæ.xæ.dæ/ pillow & /wærd/ flowers & /du:.dæ/ worm \\
\hline$/ \mathrm{r} /$ & /ra.gel/ man & 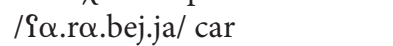 & 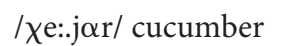 & /se.ri:.r/ bed \\
\hline$|z|$ & /z $\alpha$. r $\alpha . f \alpha . /$ giraffe & /g $\alpha . . z \alpha . r /$ carrot & /mo:z/ banana & /bæ.zæ.zæ/ bottle \\
\hline /s/ & /sæ.iæ/ watch & /fos.tæn/ dress & /b $\alpha . t \alpha$. tes/ potato & 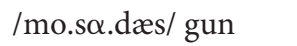 \\
\hline$/ \int /$ & $/ \int \alpha n . t \alpha /$ bag & $/ \mathrm{me} \cdot \int \underline{\mathrm{t}} / \mathrm{comb}$ & /do.s/shower & 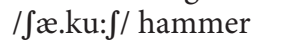 \\
\hline /s $/$ & /s $\alpha$. bu:næ/ soap & /ho.s $\alpha:$ n/ horse & /PQ.mi:s / shirt & $/ \mathrm{m} \alpha . \underline{s} \alpha . \underline{s} \alpha /$ lollipop \\
\hline$/ \underline{\mathrm{d}} /$ & / dof.d $\alpha . \Upsilon /$ frog & $/ \mathrm{m} \alpha \underline{\mathrm{d}} \cdot \mathrm{r} \alpha \mathrm{b} / \mathrm{bat}$ & /be: $\underline{\mathrm{d}} /$ egg & $/ \mathrm{I} \alpha \cdot \underline{\mathrm{d}} \alpha \cdot \overline{\mathrm{d}} \alpha /$ teether \\
\hline$/ \underline{t} /$ & $/ \underline{t} \alpha b . l \alpha /$ drum & /bon.ta.lo:n/ trousers & $/ \mathrm{me} \int \mathrm{t} / \mathrm{comb}$ & /t $\alpha . \bar{m} \alpha . t e m /$ tomato \\
\hline$|\underline{z}|$ & /z $\alpha$.bet/ policeman & $/ \underline{\mathrm{m} \hbar} \cdot \overline{\mathrm{f}} \alpha \cdot \underline{\mathrm{z}} \alpha /$ wallet & / $\alpha \mathrm{l} . \mathrm{m} \alpha: \underline{z} /$ diamond & - \\
\hline $\mid \overline{\mathrm{I}} /$ & / $\alpha$ s.fu.r $\alpha /$ sparrow & /mæi.læiæ/ spoon & /gæ.mei// mosque & /nei.næ:i/ mint \\
\hline$/ \gamma /$ & / yæs.sæ.læ/ washing machine & /mo. $\gamma æ n . n i / s i n g e r$ & /s $\alpha \mathrm{m} \gamma /$ glue & 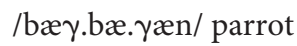 \\
\hline /f/ & /fos.tæn/ dress & /mof.tæh/ key & / $\chi \alpha$. ru:f/ sheep & /fel.fel/ green paper \\
\hline$/ \mathrm{k} /$ & /ko.r $\alpha /$ ball & /sæ.mæ.kæ/ fish & / $\int$ eb.bæk/ window & /kæh.k/ cake \\
\hline /l/ & /læ.mu:n/ lemon & /tæ.læ.gæ/ fridge & /fi:1/ elephant & /fel.fel/ green paper \\
\hline$/ \mathrm{m} /$ & $/ \mathrm{m} \alpha \underline{s} . \underline{\mathrm{t}} \alpha \cdot \mathrm{r} \alpha /$ ruler & $/ \operatorname{lom} . \mathrm{b} \alpha / \operatorname{lamp}$ & /Pæ.læm/ pencil & /t $\alpha \cdot \mathrm{m} \alpha . \operatorname{tem} /$ tomato \\
\hline$/ \mathrm{n} /$ & /n $\alpha . \operatorname{d} \alpha . r \alpha /$ glasses & /hæ.næ.fej.jæ/ fountain & / e:n/ eye & /nu:.nu:/ baby \\
\hline$/ \mathrm{h} /$ & /ho.r $\alpha \mathrm{m} /$ pyramid & /ma.hæl.læ.bej.jæ/ pudding & /sæ.iæh/ watch & /hod.hod/ hoopoe \\
\hline /w/ & /wæ.læd/ boy & $/ m \alpha$ r.w $\alpha . \hbar \alpha /$ fan & /how/ dog barking & - \\
\hline$/ \mathrm{j} /$ & /jos.mi:n/ jasmine & /t $\alpha . j$ ar $\alpha . /$ plane & $/ \int æ j /$ tea & /ju.ju/ yoyo \\
\hline
\end{tabular}




\begin{tabular}{|c|c|}
\hline Vowels & Words \\
\hline /i/ & /9e.næb/grapes \\
\hline /i:/ & /fi:l/ elephant \\
\hline /e:/ & /fe:n/ eye \\
\hline$/ \alpha /$ & /bot.tii: $\chi /$ watermelon \\
\hline$/ \alpha: /$ & $/ \mathrm{f} \alpha: \mathrm{r} / \mathrm{rat}$ \\
\hline /o:/ & /mo:z/ bananas \\
\hline$/ \mathrm{u} /$ & /kur.si:/ chair \\
\hline /u:/ & /fu:l/ beans \\
\hline
\end{tabular}

\section{References}

1 Harrell RS: The Phonology of Colloquial Egyptian Arabic. New York, American Council of Learned Societies, 1957.

2 Al-Ani S: Arabic Phonology. The Hague, Mouton, 1970.

- 3 Ali L, Daniloff RG: A contrastive cinefluorographic investigation of the articulation of emphatic-nonemphatic cognate consonants. Stud Ling 1972;26:81-105.

-4 Amayreh MM, Dyson AT: The acquisition of Arabic consonants. J Speech Lang Hear Res 1998;41:642-653.

5 Amayreh MM, Dyson AT: Phonetic inventories of young Arabic-speaking children. Clin Ling Phonet 2000;14:193-215.

6 Omar M: The Acquisition of Egyptian Arabic as a Native Language. The Hague, Mouton, 1973.

7 Ammar W, Morsi R: Phonological development and disorders: colloquial Egyptian Arabic; in Hua Z, Dodd B (eds): Phonological Development and Disorders in Children: A Multilingual Perspective. Clevedon, Multilingual Matters, 2006.
8 Paul R: Language Disorders from Infancy through Adolescence: Assessment and Intervention. St Louis, Mosby, 1995, pp 288 290.

9 Fluharty NB: Fluharty Preschool Speech and Language Screening Test: Examiner Manual, ed 2. Austin, Pro-Ed, 2001.

10 Kotby MN, Bassiouny S, Elzomor M, Mohsen $\mathrm{N}$ : Pilot study for standardization of an articulation test. Proc 10th Annu Ain-Shams Med Congr, Cairo, 1985.

11 Morsi R: A tentative articulation test for phonologically disordered Egyptian children. Child Language Seminar. University of New Castle upon Tyne, 2003.

12 Hamdan JM, Amayreh MM: Consonant profile of Arabic-speaking school-age children in Jordon. Folia Phoniatr Logop 2007;59;5564.

13 Mullen PA, Whitehead RL: Stimulus picture identification in articulation testing. J Speech Lang Hear Disord 1977;42:113-118.

14 Kaplan HI, Sadock BJ: Comparative Textbook of Psychiatry, ed 6. Baltimore, Williams \& Wilkins, 1995.
15 Morrison JA, Shriberg LD: Articulation testing versus conversational speech sampling. J Speech Lang Hear Res 1992;35:259-273.

16 Ziegler W, von Cramon D: Vowel distortion in traumatic dysarthria: a formant study. Phonetica 1983;40:63-78.

17 Morsi R: Phonological acquisition of Egyptian child from age of two and half to five years. 15th ICPHS Conf, Barcelona, 2001

18 Saleh M, Shoeib R, Hegazi M, Ali P: Early phonological development in Arabic Egyptian children: 12-30 months. Folia Phoniatr Logop 2007;59:234-240.

19 Templin M, Darley F: The Templin-Darley Tests of Articulation, ed 2. Iowa City, University of Iowa Bureau of Educational Research and Service, 1969.

20 Shanks S, Shapre M, Jackson B: Spontaneous responses of first grade children to diagnostic picture articulation test. J Commun Disord 1970;3:106-117.

21 Madison CL, Kolbeck CP, Walker JL: An evaluation of stimuli identification on three articulation tests. Lang Speech Hear Serv Sch 1982;13:110-115. 